\title{
Nutritional strategies to optimize dairy cattle immunity ${ }^{1}$
}

\author{
L. M. Sordillo ${ }^{2}$ \\ College of Veterinary Medicine, Michigan State University, East Lansing 48824
}

\begin{abstract}
Dairy cattle are susceptible to increased incidence and severity of both metabolic and infectious diseases during the periparturient period. A major contributing factor to increased health disorders is alterations in bovine immune mechanisms. Indeed, uncontrolled inflammation is a major contributing factor and a common link among several economically important infectious and metabolic diseases including mastitis, retained placenta, metritis, displaced abomasum, and ketosis. The nutritional status of dairy cows and the metabolism of specific nutrients are critical regulators of immune cell function. There is now a greater appreciation that certain mediators of the immune system can have a reciprocal effect on the metabolism of nutrients. Thus, any disturbances in nutritional or immunological homeostasis can provide deleterious feedback loops that can further enhance health disorders, increase production losses, and decrease the availability of safe and nutritious dairy foods for a growing global population. This review will discuss the complex interactions between nutrient metabolism and immune functions in periparturient dairy cattle. Details of how either deficiencies or overexposure to macro- and micronutrients can contribute to immune dysfunction and the subsequent development of health disorders will be presented. Specifically, the ways in which altered nutrient metabolism and oxidative stress can interact to compromise the immune system in transition cows will be discussed. A better understanding of the linkages between nutrition and immunity may facilitate the design of nutritional regimens that will reduce disease susceptibility in early lactation cows.
\end{abstract}

Key words: dairy cow, immunity, inflammation, metabolic stress

Received September 5, 2015.

Accepted October 25, 2015.

${ }^{1}$ Presented as part of the ADSA Production Division Symposium: The Rumen and Beyond-Nutritional Physiology of the Modern Dairy Cow at the ADSA-ASAS Joint Annual Meeting, Orlando, Florida, July 2015.

${ }^{2}$ Corresponding author: sordillo@msu.edu

\section{INTRODUCTION}

Diseases of food animals represent a major deterrent to a profitable and sustainable animal agriculture sector. Dairy cattle in particular are susceptible to increased incidence and severity of both metabolic and infectious diseases during the periparturient period. Health problems occurring around the time of parturition are especially problematic because they greatly affect the productive efficiency of cows in the ensuing lactation. Direct economic losses associated with periparturient health disorders include reductions in the cow's productive capacity and increased mortality rates. Indirect economic losses associated with dairy cattle diseases include the costs of antimicrobial drugs, vaccines, and surveillance measures, and the labor needed to implement treatment and control measures (Pritchett et al., 2005). The ability of dairy cattle to resist the establishment of diseases during the periparturient period is related, in part, to the efficiency of their immune system. The immune system consists of a variety of biological components and processes that serve to protect animals from the consequences of disease. The primary roles of the immune system are to prevent microbial invasion of the body, eliminate existing infections and other sources of cellular injury, and restore tissues to normal function. In dairy cattle, the immune system utilizes a multifaceted network of physical, cellular, and soluble factors to facilitate defense against a diverse array of microbial challenges (Mallard et al., 1998; Rainard and Riollet, 2006; Aitken et al., 2011). This integrated system of defense mechanisms is highly regulated to maintain a delicate balance between the activation of immunity needed to prevent establishment of disease and the resolution of activity once the threat of invasion has passed. This paper will provide a brief overview of the bovine immune system, describe how suboptimal immune responses can fail to prevent disease, describe the interrelationship between nutrition and immune functions, and outline current strategies to optimize immune responses in dairy cows during times of increased susceptibility to disease. Given the critical role that nutrition plays in supporting all immune functions, nutritional-based management 
strategies should have a central position in any disease prevention program.

\section{IMMUNE SYSTEM OVERVIEW}

A properly functioning immune system should protect dairy cows from a variety of pathogenic organisms, including viruses, bacteria, and parasites. To accomplish this task, the immune system utilizes a complex and dynamic network of tissues, cells, and molecules that can be conveniently separated into 2 distinct categories: innate immunity and adaptive or acquired immunity. The innate immune system is characterized by an early and rapid response that can occur within seconds following the initial tissue insult. Innate immunity is broad in scope with the capacity to respond to any tissue injury or neutralize a wide variety of potential pathogens. The adaptive immune system is delayed compared with innate immunity and can take several days to mount a response. Adaptive immunity is a more customized or specific response to infectious pathogens and can be augmented by repeated exposure to the same microbe. Collectively, the innate and adaptive immune systems must work synergistically to provide optimal protection from external threats and survival of the cow. Previous reviews provided detailed descriptions of the bovine immune system within the context of the periparturient cows (Mallard et al., 1998; Sordillo and Streicher, 2002; Aitken et al., 2011). Therefore, this review will provide only a brief overview of the major components of dairy cattle immunity with more emphasis on how nutritional status and specific nutrients affect essential aspects of host defense.

\section{Innate Immune System}

The innate immune system is the dominant host defense mechanism in most organisms. Innate immunity includes the nonspecific components of the immune system that can respond to infectious microbes in a generic manner. Constituents of innate immunity represent the first line of defense against invading pathogens because they are already present or are activated quickly at the site of pathogen exposure. Depending on the efficiency of innate defenses, microbes may be eliminated within minutes to hours following invasion. This initial line of defense can be so rapid and efficient that there may be no noticeable changes in normal physiological functions of tissues as a consequence of the attempted microbial invasion. Because of its nonspecific nature, however, the innate immune mechanism is not augmented by repeated exposure to the same insult. Major components of the innate immune system include physical and mechanical barriers, phagocytes, vascular endothelium, and various soluble mediators derived from both immune and nonimmune cell populations within affected tissues (Table 1). Physical and mechanical barriers are essential for preventing pathogens from entering the body. Some examples of surface barrier defenses that impede microbial invasion include the skin, tears, and mucus. Once pathogens are able to breach this initial line of defense, however, the cellular and soluble components of the innate immune response must act promptly to prevent the successful establishment of disease.

Pattern recognition receptors (PRR) play a critical role in innate immunity by sensing the presence of invading pathogens that successfully breach surface barrier defenses. These PRR function to recognize a range of microbial factors associated with infectious pathogens and can be expressed on cell surfaces, secreted, or expressed intracellularly (Jungi et al., 2011; Kumar et al., 2011). The first PRR identified was Toll in Drosophila melanogaster, and the toll-like receptors (TLR) are now among the most widely studied PRR in mammals (Kawai and Akira, 2011). At least 10 different bovine TLR have been identified and can bind a range of microbial products and endogenous ligands collectively referred to as pathogen-associated molecular patterns (PAMP; McGuire et al., 2006). Some examples of PAMP that are unique to specific groups of

Table 1. Components of the innate immune system

\begin{tabular}{|c|c|}
\hline Factor & Main functions \\
\hline Physical barriers & Block and trap microbes (skin, tears, mucus) \\
\hline Pattern recognition receptors & Surveillance and activation of innate immune responses \\
\hline Complement & Bacteriolytic and facilitates phagocytosis \\
\hline Cytokines & Immunoregulatory for innate and adaptive immunity \\
\hline Oxylipids & Proinflammatory and proresolving \\
\hline Endothelial cells & Regulates leukocyte migration and activation \\
\hline Neutrophils & $\begin{array}{l}\text { Phagocytosis; antibacterial enzymes, defensins, and reactive oxygen species; neutrophil extracellular trap } \\
\text { (NET) formation }\end{array}$ \\
\hline Macrophages & Phagocytosis; production of cytokines and oxylipids \\
\hline Dendritic cells & Phagocytosis; links innate and adaptive immunity \\
\hline Natural killer cells & Targets and helps to eliminate infected host cells \\
\hline
\end{tabular}


microbes include lipopeptides of gram-positive bacteria and LPS of gram-negative bacteria (Jungi et al., 2011; Kumar et al., 2011). Examples of PRR found in both immune and nonimmune cells that can differentiate a range of PAMP are cluster of differentiation (CD)14, nucleotide-binding oligomerization domains, and the family of TLR, including TLR2, TLR4, TLR5, and TLR9. After binding to their ligand, PRR can begin intracellular signaling cascades that result in initiation of innate immune responses or can facilitate antimicrobial activity directly (Kumar et al., 2011).

When microbes successfully invade host tissues, they are confronted by several endogenous soluble defenses of innate immunity. Depending on the site of invasion, some of these soluble factors can be pre-existing or induced through signaling cascades upon recognition of microbial factors by PRR on host cells. Complement, for example, is a component of the innate defense system that consists of a collection of proteins present in serum and other body fluids that can interact with other immune mediators such as cytokines to amplify antimicrobial mechanisms (Hajishengallis and Lambris, 2010). The proteins that comprise the complement system are synthesized mainly by hepatocytes, but other cellular sources include monocytes and tissue macrophages. The complement cascade consists of several different effector molecules including complement factors C3, C5a, and the C5b-9 complex (Hajishengallis and Lambris, 2010). Activation of the complement system can result in direct bactericidal activities from the deposition of pore-forming complexes onto the surface of bacteria. Other important biological functions of complement that contribute to early microbial killing include opsonizing bacteria and priming or activating host immune cells for phagocytosis and intracellular killing. Complement also is a potent chemoattractant responsible for the recruitment and activation of inflammatory cells (neutrophils and monocytes) during the early stages of infection (Rainard, 2003). Similar to TLR, complement is able to recognize conserved microbial structures such as cell wall components and carbohydrate motifs through a pattern recognition approach (Hajishengallis and Lambris, 2010).

Cytokines are an excellent example of soluble innate defenses that are dynamically induced following activation of PRR by PAMP. For example, LPS is a potent PAMP that can bind to TLR4 in complex with CD14 and LPS-binding protein. The activation of TLR4 can then lead to induction of several inflammatory pathways, including the mitogen-activated protein kinase and nuclear factor $\kappa \mathrm{B}(\mathbf{N F} \kappa \mathbf{B})$ signaling cascades, where enhanced cytokine expression is a major response (Takeuchi and Akira, 2010). The cytokine network consists of a diverse group of proteins produced by both im- mune and nonimmune cells throughout the entire body and under diverse circumstances. The physiological and immunomodulatory capacity of the cytokine network is complex. Individual cytokines can interact with other cytokines synergistically, additively, or antagonistically on multiple cell targets. Several different cytokines can affect biological processes in the same way, as there is considerable functional redundancy within the cytokine network. For example, tumor necrosis factor- $\alpha$ (TNF $\boldsymbol{\alpha})$ and IL1 $\beta$ are expressed rapidly during the initial stages of infection and have potent proinflammatory functions, whereas IL4, IL10, and IL17 actively promote the resolution of the inflammatory cascade (Bannerman, 2009). Most cytokines have very short half-lives, so their synthesis and function usually occur in bursts of activity. Cytokines are able to influence cellular functions through high-affinity receptors for each cytokine located on host cells. Therefore, the activity of any responder cell is a function of not only the quantity and type of cytokine in the tissue microenvironment but also the relative expression of cytokine receptors (Sordillo and Streicher, 2002; Bannerman, 2009). With respect to innate immunity, cytokines exert their diverse effects by initiating the inflammatory response and facilitating the migration of leukocytes from blood into infected tissues following bacterial recognition by local cell populations (Ryman et al., 2015a). The pattern of cytokine expression by cells in the body will differ depending on the type of pathogen that elicits their response. In general, however, gram-negative bacteria initiate a greater magnitude of proinflammatory cytokine responses (i.e., IL1, IL6, IL8, and TNFo) compared with gram-positive bacteria, which tend to express a weaker and slower cytokine response during the early stages of infection (Bannerman, 2009).

Oxylipids are another group of important immune signaling molecules that are derived from cellular lipids and contribute to innate immunity by regulating the onset, magnitude, and duration of the inflammatory response. Oxylipids are synthesized from PUFA substrates primarily found in the cellular membrane, including the n-6 (omega-6) linoleic and arachidonic acids or the n-3 eicosapentaenoic acid (EPA) and docosahexaenoic acid (DHA; Raphael and Sordillo, 2013). These fatty acid substrates are oxidized nonenzymatically by reactive oxygen species (ROS) or through different enzymatic pathways including the cyclooxygenases (COX), lipoxygenases (LOX), and cytochrome P450 pathways to produce a variety of oxylipids including prostaglandins (PG), thromboxanes (TX), leukotrienes (LT), and lipoxins. Depending on the timing and magnitude of expression, certain oxylipids can either enhance or resolve the inflammatory response (Serhan et al., 2008; Sordillo and Raphael, 2013). Therefore, the balance between 
production of pro- and antiinflammatory oxylipids is one factor that determines the inflammatory phenotype of a cell and the surrounding microenvironment.

\section{Inflammation}

Inflammation is a critical component of the innate defense system that involves complex biological responses of both cellular and soluble factors following local tissue injury or trauma. The purpose of host inflammatory responses is to eliminate the source of tissue injury, restore immune homeostasis, and return tissues to normal function. The inflammatory cascade results not only in the escalation of local antimicrobial factors, but also in the increased movement of leukocytes and plasma components from the blood into infected tissues (Aitken et al., 2011; Ryman et al., 2015a). The clinical signs of inflammation include redness, heat, swelling, and pain. These clinical symptoms can be explained by distinct changes in vascular endothelial responses. For example, redness, heat, and pain are caused by increased blood flow as a consequence of enlarged vascular diameter. Increased vascular permeability, resulting from the separation of tightly joined endothelial cells that line the blood vessel, leads to the exit of fluids and proteins from the blood and accumulation in tissues. These events account for the swelling or edema associated with inflammation (Ryman et al., 2015a).

In addition to changes in blood flow, the vascular endothelium also serves as a gate-keeper that regulates the movement of leukocytes from the blood vessels and into the affected tissues. Local immune and nonimmune cell populations can become active by PAMP and then release various inflammatory mediators such as cytokines and oxylipids that initiate the inflammatory cascade. These inflammatory mediators act directly on vascular endothelium to cause reductions in blood velocity with a concomitant increased expression of adhesion molecules on endothelial cells (Ryman et al., 2015a). Adhesion molecules on leukocytes attach to vascular adhesion molecules to facilitate the migration of leukocytes from the blood to the site of injury (Maddox et al., 1999; Hodgkinson et al., 2007). Neutrophils are the predominant cell type to undergo this extravasation process during the early stages of inflammation. Neutrophils first marginate and then adhere to the local endothelium near the site of infection. Cytokines, oxylipids, and other mediator molecules stimulate adherent neutrophils to move between endothelial cells and pass the basement membrane into the damaged tissue areas (Aitken et al., 2011; Ryman et al., 2015a). The movement of neutrophils within tissues is facilitated by chemotactic gradients created by inflammatory mediator molecules at the localized site of infection. Neutrophil migration can occur quickly and accumulate within affected tissues as soon as 30 to $60 \mathrm{~min}$ following injury (Summers et al., 2010).

Both newly recruited and pre-existing leukocyte populations act cooperatively to eliminate microbial pathogens. Macrophages localized within tissues respond to bacterial invasion by the release of immuneregulatory cytokines and oxylipids. Macrophages, dendritic cells, and the newly recruited neutrophils also function to phagocytize and kill invading microbes. The process of phagocytosis involves the internalization of bacteria within phagosomes that contain bactericidal ROS and hydrolytic enzymes. The ROS are formed by respiratory burst activity that involves the activation of NADPH oxidase and subsequent production of superoxide radicals and hydrogen peroxide (Babior, 1999). Myeloperoxides can further combine hydrogen peroxide with chloride to produce hypochlorite, which is associated with bacterial activities. In addition to phagocytosis, neutrophils can kill bacteria through extracellular mechanisms. Activated neutrophils can form neutrophil extracellular traps (NET) that consist of a web of fibers composed of chromatin and serine proteases that trap and kill bacteria. Studies suggest that NET provide highly concentrated foci of antibacterial substances that bind and kill bacteria independently of phagocytic uptake in the mammary gland (Lippolis et al., 2006b; Grinberg et al., 2008). In addition, NET may serve as a physical barrier to prevent further spread of bacteria throughout the cow's tissues.

\section{Adaptive Immunity}

The adaptive immune response is triggered when innate immune mechanisms fail to eliminate a pathogen. The adaptive immune response is characterized by the generation of antigen-specific lymphocytes and memory cells with the ability to recognize specific antigenic determinants of a pathogen. When host cells and tissues are re-exposed to the same antigen, a heightened state of immune reactivity occurs as a consequence of immunological memory and clonal expansion of antigen-specific effector cells. A memory immune response would be much faster, considerably stronger, longer lasting, and often more effective in clearing an invading pathogen compared with a primary immune response. In contrast to the innate immune response, adaptive immunity can take days to develop because of the clonal expansion of $\mathrm{B}$ and $\mathrm{T}$ lymphocytes specific to the invading pathogen. An amazing feature of the immune system is the ability of a host to recognize and respond to billions of unique antigens that they may encounter. It also is important that an inappropriate specific immune response does not occur against the host's own antigens. For this rea- 
Table 2. Components of the adaptive immune system

\begin{tabular}{ll}
\hline Factor & Main functions \\
\hline Major histocompatibility complex & Recognizes self from non-self \\
Dendritic cells and macrophages & Antigen presentation cells \\
T Lymphocytes & T helper cells (Th1, Th2, Th17, Treg); produce cytokines that regulate innate and adaptive \\
& immunity; immunoglobulin isotype switching \\
& T cytotoxic cells (Tc); attack and kill cells that express foreign antigens (virus-infected) \\
& Prevalent in ruminants and found at mucosal surfaces; important antimicrobial defense \\
& Mature B cells are antigen-presenting cells and expand into antigen-specific memory cells \\
B lymphocytes & Plasma cells synthesize and secrete antigen-specific antibodies \\
& IgM is the largest and first produced; role in agglutination and complement activation \\
IgG concentration is high in sera and is important for opsonization & IgA is found at mucosal surfaces and has anti-viral function \\
IgE is associated with allergic reactions and parasitic infections \\
IgD is a nonsecreted regulatory molecule
\end{tabular}

son, the immune system is able to distinguish self from non-self and selectively react to only foreign antigens. Genetically diverse, membrane-bound proteins called major histocompatibility complex (MHC) molecules assist in this recognition. A specific immune response will only occur if antigens are combined with an $\mathrm{MHC}$ molecule on the surface of certain cells, a process referred to as antigen presentation (Kazansky, 2008). The unique features of the adaptive immune response form the basis of vaccine strategies (Table 2).

Generation of effective adaptive immunity involves 2 categories of cells: lymphocytes and antigen-presenting cells. Lymphocytes recognize bacterial antigens through membrane receptors specific to the invading pathogens. These are the cells that mediate the defining attributes of adaptive immunity including specificity, diversity, memory, and recognition of self and non-self. The $\mathrm{T}$ and $\mathrm{B}$ cells are distinct subsets of lymphocytes that differ in function and protein products. The T cells can be further subdivided into $\alpha \beta \mathrm{T}$ cells, which include CD4+ (T helper, Th), CD8+ (T cytotoxic, Tc), and $\gamma \delta \mathrm{T}$ cells. Further characterization of Th cells has led to more refined functional groups that include Th1, Th2, Th17, and T regulatory cells (Treg). Depending on tissue location, the percentages of these cells can vary significantly.

Effector functions of $\mathrm{T}$ cells include the production of cytokines that facilitate cell-mediated immunity by regulating the magnitude and duration of the immune response. The Th cells (Th1, Th2, Th17, and Treg) produce cytokines in response to recognition of antigenMHC complexes on antigen-presenting cells (B cells, dendritic cells, and macrophages). When activated, Th cells produce a variety of immunoregulatory cytokines. Through the ability to secrete certain cytokines, Th cells play an important role in activating $\mathrm{T}$ and $\mathrm{B}$ cells, macrophages, neutrophils, and various other cells that participate in the immune response. Differences in the particular pattern of cytokines produced by activated Th cells results in different types of immune responses (Sordillo and Streicher, 2002). The Tc cells can exert cytotoxic functions when activated. Cytotoxic T cells recognize and eliminate altered self cells via antigen presentation in conjunction with $\mathrm{MHC}$ class I molecules. There is some speculation that Tc cells may act as scavengers that remove old or damaged secretory cells in the mammary gland. Similar to the Th cells, Tc are thought to control or modulate the immune response by the repertoire of cytokines that they produce (Aitken et al., 2011). The biological functions of $\gamma \delta \mathrm{T}$ cells have been the subject of much speculation. The percentage of $\gamma \delta \mathrm{T}$ cells in bovine PBMC populations is high compared with PBMC in humans (Baldwin and Telfer, 2015). Their functions are primarily associated with the protection of epithelial surfaces and possibly mediate cytotoxicity with variable involvement of MHC. Surface molecules (WC1) unique to $\gamma \delta \mathrm{T}$ cells act as co-receptors used for both recognition of microbial pathogens and for signaling cell activation. These cells play a role in infectious diseases and therefore provide an important line of defense against bacterial diseases (Baldwin and Telfer, 2015).

Antigen-specific B cells synthesize and secrete antibodies or immunoglobulins that recognize and counteract specific microbial virulence factors. Antigenactivated B cells that subsequently proliferate and differentiate into antibody-secreting plasma cells produce immunoglobulins. Several classes of immunoglobulins are known to influence host defense against infectious pathogens, which all differ in their physiochemical and 
biological properties (Table 2). For example, several immunoglobulin isotypes $\left(\operatorname{IgG}_{1}, \operatorname{IgG}_{2}\right.$, and $\left.\operatorname{IgM}\right)$ can act as opsonins to enhance phagocytosis by neutrophils and macrophages. In addition to its role in opsonization, $\operatorname{IgM}$ is efficient at complement fixation. Whereas $\operatorname{IgA}$ does not aid in bacterial opsonization, it does function in bacterial agglutination, which can impede the ability of certain pathogens to spread throughout certain tissues. Another important role of $\operatorname{IgA}$ is its ability to neutralize some bacterial toxins (Sordillo and Streicher, 2002; Aitken et al., 2011). Clearly, both the concentration and isotype composition of immunoglobulins found in tissues can have a profound influence on the establishment of new infections.

\section{Periparturient Immune Dysfunction}

The transition period is a time of increased incidence of several economically important diseases such as mastitis, metritis, displaced abomasum, and ketosis. Health disorders occurring during this time are especially problematic because they greatly affect the productive efficiency of cows in the ensuing lactation (Pinedo et al., 2010). Metabolic and infectious diseases tend to occur in complexes with each other rather than as isolated events in cows during early lactation, and an increased incidence of any single transition cow disorder will increase the chance that they will succumb to other health issues (Curtis et al., 1983). For example, epidemiological studies indicate an association between the development of retained placenta and the incidence of mastitis (Emanuelson et al., 1993). In addition, cows suffering from ketosis were twice as likely to develop mastitis as healthy cows (Oltenacu and Ekesbo, 1994). A major underlying factor thought to be responsible for the development of these transition cow disorders is immune dysfunction.

Dramatic changes in the efficiency of the bovine immune system are well documented around the time of calving. Numerous reviews have summarized major changes in many aspects of both innate and adaptive immunity that can affect the susceptibility to new diseases in cows during the periparturient period (Mallard et al., 1998; Aitken et al., 2011; Ingvartsen and Moyes, 2013). Not only are transition cows more likely to become infected when exposed to pathogenic organisms, but the severity of disease is also escalated. Dysfunctional inflammatory reactions that occur at both the systemic and local level, for example, are especially problematic because of the direct impact on disease pathogenesis in transition cows. Derangements in inflammatory responses can consist of a hyporesponsive state characterized by delayed migration of functionally adequate neutrophils and other innate immune factors during the early stages of disease. Indeed, many previous studies have described impaired neutrophil functions during the periparturient period, including impaired ROS production, myeloperoxidase activity, chemotaxis, and phagocytosis (Cai et al., 1994; Kimura et al., 1999; Mehrzad et al., 2001). The reduced capacity of neutrophils to undergo chemotaxis and produce ROS were found to be greatest in cows that later in the early lactation period developed mastitis and metritis compared with healthy herd mates (Cai et al., 1994). Conversely, the lack of an appropriate balance between the initiation and resolution of inflammation can result in an overly robust or chronic inflammatory response characterized by extensive damage to host tissues. An excellent example of the consequence of an uncontrolled inflammatory response is the severity and duration of mastitis in early lactation cows. Studies showed that the ability of mammary glands to promptly respond to Escherichia coli endotoxin during early lactation was diminished compared with that of cows in mid lactation (Grommers et al., 1989). The delayed migration of neutrophils and their reduced antimicrobial activity was thought to be the cause of more severe coliform mastitis in the periparturient period compared with later stages of lactation (Hill, 1981; Shuster et al., 1996).

The underlying causes of dysfunctional inflammation during the transition period have been the subject of considerable research, with evidence to support at least a partial role for the bidirectional interaction between the endocrine and immune systems. Indeed, research conducted using both in vitro and in vivo models found that immune cell populations not only express hormone receptors, but also are capable of producing several neuroendocrine factors (Lamote et al., 2006a; Kelley et al., 2007; Weigent, 2013). For example, increases in several steroid hormones around the time of parturition are at least partially responsible for the altered function of bovine neutrophils through specific receptor-ligand interactions (Burton et al., 2005). Glucocorticoid receptors are expressed on several immune cell populations and increased plasma glucocorticoid concentrations around the time of calving are known to have potent immunosuppressive functions (Anderson et al., 1999; Lippolis et al., 2006a; Kelley et al., 2007). For example, a mechanism by which glucocorticoids can impair bovine blood neutrophil function is by inducing a downregulation of L-selectin and CD18 adhesion molecules needed for effective activation and migration to sites of tissue injury (Burton et al., 1995). Furthermore, changes in estradiol and progesterone concentrations just before calving were reported to have direct and indirect effects on the functional capabilities of both lymphocytes and neutrophils (Roth et al., 1982; Lamote et al., 2006b). Changes in plasma concentrations 
of these steroid hormones do not overlap with the entire transition period, however, and it is probable that other hormones associated with the transition period also contribute to immune and inflammatory dysfunction. For example, several homeorhetic hormones including prolactin, growth hormone, IGF, and insulin are known to fluctuate considerably during the transition period and in association with altered metabolism and DMI (Ingvartsen and Andersen, 2000). Considerable evidence in human and rodent species suggests that both innate and adaptive immune responses are influenced by these protein hormones (Davis, 1998; Kelley et al., 2007). Thus, changes in the expression of homeorhetic hormones around the time of parturition and into early lactation could likely affect critical immune cell functions in the transition cow.

Physiological and metabolic changes associated with calving and the onset of lactation during the transition period are also implicated in the derangement of appropriate immune and inflammatory responses (Sordillo and Raphael, 2013). In a series of elegant studies, for example, pregnant dairy cows were mastectomized to assess the effect of milk production on various immune parameters while still maintaining the endocrine changes associated with late pregnancy and parturition (Kimura et al., 1999, 2002b; Nonnecke et al., 2003). The mastectomized cows experienced only moderate increases in nonesterified fatty acids (NEFA) compared with the cows with intact mammary glands during the periparturient period. Although immune function was compromised briefly around calving in mastectomized cows, lymphocyte and neutrophil functions were diminished longer in cows with mammary glands (Kimura et al., 1999; Nonnecke et al., 2003). Those authors also reported a negative effect of lactation on the composition of peripheral blood leukocyte populations (Kimura et al., 2002b). The major conclusion from these studies was that the act of parturition, with the associated changes in steroid hormone profiles, is not the major immunosuppressive factor in periparturient cows. Instead, the increased metabolic demands of early lactation were likely responsible for the adverse effect on immune cell populations. Changes in nutrient intake and availability of specific nutrients may be a common linkage between dysfunctional immune responses and the increased incidence of both metabolic and infectious diseases in periparturient dairy cattle.

\section{NUTRITION AND IMMUNE FUNCTION}

The nutritional status of dairy cows is widely recognized as being closely linked to the maintenance of optimal immune function and health. Nutritional requirements will vary considerably throughout the production cycle of dairy cows and any mismanagement of dietary requirements is associated with dysfunctional responses and associated health disorders. For example, previous studies showed that both over- and underconditioned dairy cows have higher incidences of disease than normally conditioned cows during the early lactation period (Heuer et al., 1999; Roche et al., 2009). Dry matter intake and energy balance during the dry period will result in either abnormally high or low BCS during the periparturient period. Underconditioned cows (calving BCS $<3$ on a 5 -point scale) suffer from insufficient energy and protein reserves needed for optimal milk yields, milk fat, and disease resistance (Hoedemaker et al., 2009; Roche et al., 2009). In the case of overconditioned cows (calving BCS $\geq 3.5$ on a 5 -point scale), the normal decline in DMI during the immediate prepartum period is exacerbated. The greater decline in DMI with high BCS cows results in severe negative energy balance (NEB) and excessive accumulation of plasma NEFA concentrations due to intense lipid mobilization from tissue stores. Prolonged increases in plasma NEFA both during the immediate prepartum and early postpartum periods are not well tolerated by cows and represent an important risk factor for early lactation health disorders (Heuer et al., 1999; Hoedemaker et al., 2009). Therefore, cows should be managed to achieve an appropriate BCS both pre- and postcalving to avoid adverse consequences on lactation performance and disease resistance.

\section{Negative Energy Balance and Immunity}

Reduced DMI and deeper NEB during the periparturient period can affect disease susceptibility by compromising the functional capacity of the immune system. For example, early studies showed that decreases in DMI and increased plasma NEFA concentrations were temporally correlated with impaired peripheral blood neutrophil function during the periparturient period (Kehrli et al., 1989; Cai et al., 1994). Reduced neutrophil functional capabilities during this time were associated with early lactation health disorders including retained placenta and metritis (Cai et al., 1994; Kimura et al., 2002a; Hammon et al., 2006). Moreover, decreases in neutrophil function could be identified before the detection of these uterine disorders (Hammon et al., 2006). Another associative study found that the in vitro proliferative responses of peripheral blood mononuclear cells obtained from periparturient cows were predictive of subsequent disease incidence. In that study, cows that were characterized as having low responding mononuclear cells eventually suffered from clinical mastitis, metritis, or interdigital dermatitis during the first 60 d of lactation (Catalani et al., 2013). Some conflicting 
evidence, however, suggests that the causality of periparturient immune dysfunction is more complex. Experimental feed restriction models with mid-lactation cows were used in an attempt to recapitulate the deep NEB observed around the time of calving. The idea was to use such models to determine the effect of nutrient deficiencies on immunity and disease severity. Yet, none of these studies to date have been able to mimic the extensive immunological changes that occur during the periparturient period. For example, mid-lactation cows subjected to a 5-d nutrient restriction had relatively minimal alterations in immune function following mastitis challenge (Moyes et al., 2009). Others reported that experimentally induced NEB alone had a minimal effect on the expression of bovine leukocyte adhesions or antigen-presenting molecules in cattle (Perkins et al., 2001). Furthermore, dietary-induced NEB during mid lactation had no effect on clinical symptoms following acute endotoxin-induced mastitis (Perkins et al., 2002). These data collectively suggest that although NEB and intense lipid mobilization play an important role in periparturient immune dysfunction, transient nutritional deficiencies alone are not sufficient to fully recapitulate the nutrient and metabolic imbalances that occur around the time of calving. The expression of key players in the somatotropic axis could be a contributing factor linking NEB and altered immune cell function with respect to different stages of lactation. Indeed, previous studies showed that cows in NEB had greater shifts in growth hormone and IGF1 concentrations along with more pronounced insulin resistance during early lactation compared with mid lactation (Gross et al., 2011). Given the fact that immune cell populations possess receptors for and are capable of responding to these hormones (Lamote et al., 2006a; Weigent, 2013), differences in endocrine adaptations to NEB relative to stage of lactation is likely a critical factor that can influence the functional capacity of the immune system.

\section{Fatty Acids as an Energy Source}

Although the existing evidence is compelling that NEB around calving is a major contributing factor to periparturient immune dysfunction, the precise mechanisms responsible for these effects are not fully understood. However, increased plasma NEFA concentrations during intense lipid mobilization do play at least a partial role in altering how cows respond to immune challenges during the transition period. An important way that intense NEB and increased plasma NEFA concentrations may adversely affect host defense mechanisms is by changing the availability of nutritional substrates that are needed to mount an ef- fective immune response. For example, it has long been recognized in human medicine that the availability of adequate amounts of energy is essential to optimal immune functions (Calder, 2013). An activated immune system will require considerably more energy compared with an immune system at rest. During an inflammatory response, for example, macrophages and neutrophils will participate in phagocytosis, production of ROS, biosynthesis of oxylipids, and secretion of proinflammatory cytokines, all of which require high-energy utilization (Newsholme et al., 1986). Antigen-stimulated lymphocytes undergo cellular proliferation and active secretion of cytokines and antibodies, which are other major energy-consuming functions of the immune system (Brand, 1985). Thus, cells involved in both innate and adaptive immune responses require high-energy consumption as they shift from a quiescent phenotype to a highly active state during immune challenge. Cells of the immune system can fuel their functions through available fatty acids, glutamine, or glucose with different levels of efficiency (Calder, 2013).

The distribution of energy stores in dairy cows can shift considerably during microbial challenge, which can explain changes in the efficiency of the immune response. In response to acute coliform mastitis, for example, the rate of lipolysis from adipose tissue stores increases significantly, resulting in elevated plasma NEFA concentrations (Hagiwara et al., 2014; Mavangira et al., 2015). Increased NEFA concentrations during infection can result from the catabolism of adipose tissue triggered by proinflammatory cytokines such as TNFa (Sordillo and Raphael, 2013). Increased plasma NEFA can then be used as an energy source through $\beta$-oxidation processes or used as a substrate to produce glucose through gluconeogenesis. Glucose is the primary energy source for all leukocytes, and its availability is directly linked to immune cell activation and function. Mitogen-induced lymphocyte activation is dependent upon glucose uptake and catabolism to provide the energy needed for their proliferation, and secretory activities. Glucose also plays an important role in macrophage and neutrophil activation. Both in vitro studies and human clinical trials support the concept that low glucose concentrations result in suboptimal immune responses (Calder, 2013). Because glucose is essential for leukocyte function, hyperglycemia was initially thought to be a beneficial host response to critical illness in humans, as glucose could fuel the immune system, but evidence now suggests that excessively high circulating glucose concentrations could contribute to aberrant inflammatory responses. This was best illustrated in human patients with type II diabetes mellitus, which is characterized by insulin resistance and hyperglycemia. 
Dysfunctional immune responses, such as reduced antibacterial activities of neutrophils and macrophages, contribute to impaired host-pathogen interactions during diabetes that results, in part, from altered glucose metabolism. Hyperglycemic states also can increase leukocyte activation, resulting in an unregulated or excessive inflammatory reaction in patients with diabetes that will contribute to disease pathogenesis (Calder et al., 2007; Hodgson et al., 2015). Collectively, there now exists an appreciation in human medicine that both hypoglycemia and hyperglycemia can adversely affect host immunity and disease susceptibility (Calder et al., 2007).

Based on what is known in other species, the overall distribution and utilization of energy stores may greatly affect how dairy cows respond to any type of immune challenge. Indeed, the metabolic demands associated with the periparturient period result in dramatic changes in glucose utilization and distribution such that the majority of available glucose is partitioned to the mammary gland for milk synthesis and secretion. To date, no studies have examined directly how cells of the bovine immune system compete for available glucose during the onset of copious milk synthesis and secretion. However, the rate-limiting step for glucose uptake and utilization by host cells is determined in part by the cell-surface expression of a family of glucose transporters (GLUT; Calder et al., 2007). Recent studies showed that the expression of GLUTs by resting bovine immune cells is significantly reduced during early lactation (O'Boyle et al., 2012). These findings support the concept that cells of the bovine immune system may be less competitive for glucose compared with what is used for milk production, thus explaining the phenomenon of immune dysfunction during the periparturient period. Upon endotoxin stimulation, however, the expression of GLUT on monocytes increased and was positively correlated with TNFa production, which supports the contention that glucose uptake is needed for proinflammatory functions (O'Boyle et al., 2012). Indeed, the immediate necessity of survival following pathogen invasion may lead to the partitioning of glucose to the immune system instead of to nonessential physiological responses such as reproduction and lactation. Thus, an activated immune system may divert limited nutrients away from other production-related processes and provide one likely explanation for decreased productivity of dairy cattle with health disorders.

\section{Fatty Acids and Intracellular Signaling}

Although increased plasma NEFA concentrations can indirectly affect immunity through its capacity as an energy source, ample evidence suggests that fatty acids can modify immune cell functions directly. Changes in the fatty acid composition of immune cell populations are responsible for influencing many aspects of both innate and adaptive immune responses in several different ways. For example, the types of fatty acids within the membrane phospholipid can greatly affect both membrane fluidity and function of immune cells through lipid raft formation (Raphael and Sordillo, 2013). Membrane rafts are specialized glycolipoprotein microdomains that influence membrane protein trafficking and cell receptor binding such as that involved in lymphocyte activation, antibody production, and inflammation. For example, composition and integrity of lipid rafts is essential for CD14 activation because raft-disrupting drugs can block LPS-induced TNF production such as that produced during gram-negative bacterial infections (Luo et al., 2008). Leukocyte membrane phospholipids of dairy cows contain significant proportions of palmitic and stearic acids (Contreras et al., 2010). The high SFA content can covalently modify proteins through fatty acylation and not only influence how proteins anchor to plasma membranes to alter membrane fluidity, but also affect lipid raft formation and thus cellular function (Raphael and Sordillo, 2013). In addition to altering the physical nature of cellular membranes, several types of fatty acids are able to regulate intracellular signaling pathways and transcription factor activation, leading to altered gene expression. For example, the prototypical inflammatory transcription factor $\mathrm{NF} \kappa \mathrm{B}$ is activated when TLR4 pathogen recognition receptors on host cells interact with LPS associated with the outer membrane of gram-negative bacteria (Kawai and Akira, 2011). Certain PUFA, such as EPA and DHA, were found to have anti-inflammatory functions by inhibiting LPSinduced NFKB activation through a TLR4-mediated mechanism (Lee et al., 2010). Both EPA and DHA can exert anti-inflammatory functions on $\mathrm{NF} \kappa \mathrm{B}$ signaling indirectly through their interaction with other signaling pathways, including peroxisome proliferator-activated receptor and the sterol response element binding protein family of transcription factors (Clarke, 2004). In contrast, several SFA, including lauric, myristic, and palmitic acids, were shown to activate NFrB-mediated gene expression through TLR4-dependent signaling, although there is some question of whether this is a direct or indirect action on TLR4 binding (Erridge and Samani, 2009; Lee et al., 2010). Regardless of the mechanisms, however, the overall effect of either SFA or PUFA on NFkB-induced inflammation appears to be through the modification of several genes central to the inflammatory response including $\mathrm{COX} 2, \mathrm{TNF}-\alpha$, and IL1 (Lee et al., 2010). 


\section{Fatty Acids as Oxylipid Substrates}

An additional way that the fatty acid composition of cells can influence immune responses is by regulating the production of potent lipid mediators or oxylipids that regulate essentially every aspect of the initiation and resolution of inflammatory responses. As discussed in earlier sections, oxylipids are primarily synthesized from n-6 (linoleic and arachidonic acids) or n-3 (EPA and DHA) PUFA present in cell membrane phospholipids and through several different oxidation and reduction pathways (Raphael and Sordillo, 2013). Historically, it was thought that oxylipids derived from n-6 PUFA (i.e., PG, LT, and TX) were primarily proinflammatory, whereas oxylipids biosynthesized from n-3 PUFA (i.e., protectin and resolvins) primarily promoted the resolution of inflammation (Serhan et al., 2008). With advances in analytical capabilities, it is now widely recognized that these earlier assumptions were too simplistic and that the oxylipid network is complex, highly interactive, and often cell-specific in orchestrating the onset or resolution of inflammatory responses (Arnardottir et al., 2015; Mavangira et al., 2015; Ryman et al., 2015b). The biosynthetic profiles of oxylipids and the subsequent effect that these metabolites may have on the character of the inflammatory response depend not only on the availability of diverse PUFA substrates but also the timing of their subsequent metabolism through various oxidizing pathways. For example, arachidonic acid metabolized through the COX pathway will produce oxylipids with opposing actions on vascular tone. Prostacyclin $\left(\mathrm{PGI}_{2}\right)$ causes vasodilation and inhibits platelet aggregation, whereas thromboxane A2 (TXA $\left.\mathbf{T}_{2}\right)$ promotes aggregation and vasoconstriction. Because both $\mathrm{PGI}_{2}$ and $\mathrm{TXA}_{2}$ are derived from the same intermediate COX product $\left(\mathrm{PGG}_{2}\right)$, the balanced expression of these oxylipids through different downstream enzymatic pathways is crucial for optimal vascular health and immune capabilities (Ryman et al., 2015a). Indeed, previous studies using bovine endothelial cells showed that oxidative stress can inhibit prostacyclin synthase activity and $\mathrm{PGI}_{2}$ formation, thus disrupting vascular homeostasis (Weaver et al., 2001). Moreover, previous assumptions that all COX2 and 15LOX metabolites are solely responsible for propagating the inflammatory response are no longer supported by the current literature. For example, arachidonic acid-derived $\mathrm{PGE}_{2}$ derived from the COX2 pathway has long been recognized as having many proinflammatory activities, including inducing pain and fever. Whereas increased COX2 expression during the onset of inflammation is typified by $\mathrm{PGE}_{2}$ production, enhanced COX2 expression during the resolution of inflammation is associated with the presence of other COX2-derived arachidonic acid metabolites, $\mathrm{PGD}_{2}$ and $15 \mathrm{~d}-\mathrm{PGJ}_{2}$. Both $\mathrm{PGD}_{2}$ and its dehydration end-product, $15 \mathrm{~d}_{-} \mathrm{PGJ}_{2}$, can inhibit leukocyte adhesion to endothelial cells and decrease cytokine expression by blocking NFkB activation (Pattanaik and Prasad, 1998). Evidence suggests that $\mathrm{PGE}_{2}$ may play an important role in triggering the resolution of inflammation by enhancing LOX activity and subsequent formation of the arachidonic acid-derived lipoxin A4 that has potent anti-inflammatory properties (Serhan and Chiang, 2008). Lipoxins are generated by a process of transcellular biosynthesis involving the sequential actions of LOX from at least 2 different cells types. For example, the initial oxygenation of arachidonic acid through the 15LOX pathway in human epithelial cells generates a 15HETE (15-hydroxyicosatetraenoic acid) precursor that is then metabolized through the 5LOX pathway in macrophages to produce $\mathrm{LXA}_{4}$ and $\mathrm{LXB}_{4}$. Conversely, arachidonic acid metabolism by 5LOX in leukocytes and the release of $\mathrm{LTA}_{4}$ can be converted by 15LOX in platelets for LX biosynthesis (Serhan et al., 2008). Changes in the timing and ratio of oxylipid biosynthesis through these LOX pathways were shown to be significant in dairy cattle health. Relative to mastitis, for example, an imbalance of the $\mathrm{LXA}_{4}: \mathrm{LTB}_{4}$ ratio occurs during chronic mastitis and is reportedly due to the dramatic reduction in $\mathrm{LXA}_{4}$ biosynthesis within infected mammary glands (Boutet et al., 2003). Recently, the use of liquid chromatography-tandem mass spectrometry provided a more robust methodology to identify an expanded oxylipid network during bovine mastitis. The major findings from that study were that oxylipids synthesized through both the LOX and cytochrome P450 pathways were the most abundant lipid mediators produced during acute coliform mastitis (Mavangira et al., 2015). With improved analytical techniques available, it is now clear that oxylipid biosynthesis during mastitis is extremely complex and dependent upon PUFA substrate availability, activity of biosynthetic pathways, and the degree by which each oxidized product is further metabolized within the mammary gland environment.

The possibility of using dietary intervention strategies to modify the substrate availability for oxylipid biosynthesis during health and disease has received some research interest. For example, feeding supplemental n-3 PUFA attenuated endometrial $\mathrm{PGF}_{2 \alpha}$ production and improved uterine health in early lactation cows (Mattos et al., 2004; Dirandeh et al., 2013). The functional properties of lymphocytes and mononuclear cells in transition cows were also modulated when n-3 fatty acids were supplemented into the diet (Lessard et al., 2004). Moreover, a large field trial was conducted in which the diets of prepartum cows were modified to reduce the n- 6 to n-3 fatty acid ratio. The authors 
Table 3. Antioxidant mechanisms provided by micronutrients

\begin{tabular}{lll}
\hline Nutrient & Active component & Function \\
\hline Vitamin A & $\beta$-Carotene & Prevents fatty acid peroxidation chain reaction \\
Vitamin C & Ascorbic acid & Radical scavenger \\
Vitamin E & $\alpha$-Tocopherol & Disrupts fatty acid peroxidation chain reaction \\
Selenium & Thioredoxin reductase & Redox signaling and reduces reactive oxygen species (ROS) \\
Selenium & Glutathione peroxidase & Redox signaling and reduces ROS \\
Copper & Ceruloplasmin & Oxidase activity; peroxyl radical scavenger \\
Copper-zinc & Superoxide dismutase & Converts cytosol superoxide to $\mathrm{H}_{2} \mathrm{O}_{2}$ \\
Zinc & Metallothionein & Cysteine rich radical scavenger \\
Manganese & Superoxide dismutase & Converts mitochondrial superoxide to $\mathrm{H}_{2} \mathrm{O}_{2}$ \\
Iron & Catalase & Converts $\mathrm{H}_{2} \mathrm{O}_{2}$ to water \\
\hline
\end{tabular}

reported improved innate immunity in cows supplemented with n- 6 fatty acids as indicated by better acute phase responses and enhanced neutrophil function during the transition period (Silvestre et al., 2011). The direct effect of increasing the n-3 PUFA content of immune cells was also assessed. Using cultured bovine endothelial cells, previous studies showed that proinflammatory responses could be mitigated in response to high NEFA concentrations that mimic intense lipid mobilization in transition cows (Contreras et al., 2012a,b). These in vitro studies provided the first direct evidence that reduced inflammatory responses may be a result of shifts in oxylipid profiles following $n-3$ supplementation as there were significant changes in the expression of proresolving oxylipids such as resolvins, protectins, and lipoxins (Contreras et al., 2012a). Collectively, the current literature supports the concept that supplementing the diets of cows with PUFA can affect oxylipid biosynthesis and effectively alter the functional capacity of cells involved in immune and inflammatory responses.

\section{Micronutrients, Oxidative Stress, and Immunity}

A balanced supply of dietary micronutrients (vitamins and trace minerals) is widely recognized in the dairy industry as having an essential role in ensuring production efficiency and immune competence in early lactation dairy cows (Table 3). Indeed, deficiencies in certain vitamins and trace minerals during the periparturient period are associated with an increased incidence of several health disorders such as mastitis, retained placenta, and metritis (Zhao et al., 2015). The various micronutrients that support fundamental immune functions and influence the incidence of health disorders in dairy cattle have been the focus of several comprehensive reviews (Wilde, 2006; Andrieu, 2008; Spears and Weiss, 2008; Sordillo and Aitken, 2009) and will not be covered in detail in this paper. Instead, this review will explore the common underlying mechanism by which most micronutrients are known to influence the functional capacity of immune cell populations and affect disease incidence and severity.

A common mechanism by which most micronutrients function within the context of optimizing immunity is through their antioxidant capabilities. Antioxidants can be broadly defined as any substance that delays, prevents, or removes oxidative damage to target macromolecules (Valko et al., 2007; Sordillo and Aitken, 2009). The loss of reduction-oxidation (redox) homeostasis and damage to tissues that results from the accumulation of excessive ROS or depletion of antioxidant defenses is referred to as oxidative stress. Previous studies have shown that oxidative stress is an important factor that can contribute to dysfunctional inflammatory responses in metabolically stressed cows during the transition period due to imbalances in the expression of ROS and the availability of antioxidant defenses (Sordillo and Aitken, 2009). A source of ROS in transition cows results as a consequence of converting nutrients to an energy source needed to fuel copious milk synthesis and secretion occurs through a series of metabolic reactions collectively referred to as cellular respirations. Reactive oxygen species are metabolites formed in the mitochondria as byproducts of the mitochondrial electron transport chain (Valko et al., 2007). In dairy cows, another important source of ROS during the transition period is from peroxisomal $\beta$-oxidation in the liver during fatty acid metabolism (Drackley, 1999; Grum et al., 2002). Most ROS found in healthy tissues likely result from increased cellular metabolism and energy generation by the mitochondria. However, other potential sources of ROS include various oxidizing enzyme pathways associated with the inflammatory response. For example, the NADPH oxidase system found in phagocytic immune cells generates significant amounts of ROS during the respiratory burst to kill microbial pathogens (Babior, 1999). Oxylipid biosynthesis during an inflammatory response can also generate considerable ROS. Membrane phospholipids can undergo enzymatic oxygenation through the COX, LOX, 
or cytochrome $\mathrm{P} 450$ pathways, resulting in not only a highly reactive lipid hydroperoxide but also superoxide anion as a byproduct of the reaction (Raphael and Sordillo, 2013). The production of some ROS from these various sources is essential for the regulation of normal cellular processes, including those that control immune and inflammatory responses. For example, evidence suggests that ROS serve as messengers in a variety of redox-regulated signaling pathways, such as NFkB and the mitogen-activated protein kinase pathway, that lead to the production of cytokines, oxylipids, and other immunoregulatory factors essential for optimal immune and inflammatory responses (Finkel, 2011; Brown and Griendling, 2015). Thus, low to moderate amounts of ROS can be beneficial to the health of dairy cows when confronted with microbial challenge or other sources of tissue injury.

Health problems occur, however, when antioxidant defenses are inadequate and ROS accumulation becomes excessive, causing damage to tissue macromolecules such as DNA, proteins, and lipids. In humans, for example, hydroxyl radicals can cause breaks in DNA strands, modifications of purine and pyrimidine bases, and alterations in deoxyribose sugar molecules associated with cancer and aging (Valko et al., 2007). The primary targets of ROS damage, however, are lipids and there is significant evidence in dairy cattle that excessive lipid peroxidation occurs during the transition period (Bernabucci et al., 2005; Sordillo et al., 2007; Sordillo and Aitken, 2009). Lipid peroxidation involves a chain reaction process initiated when ROS, such as hydroxyl radicals, acquire electrons from lipids in cellular membranes. The abstraction of electrons from fatty acids results in the generation of a lipid peroxy radical that causes an autolytic chain reaction within the plasma membrane, where additional electrons are removed from adjacent fatty acid. Lipid peroxidation products can damage cellular membranes and organelles that in turn alter cellular functions and signal transduction. Controlled studies using cultured bovine endothelial cells provide direct evidence that conditions of oxidative stress will increase production of lipid hydroperoxides and exacerbate the inflammatory responses and dysfunction of the vascular endothelium (Sordillo et al., 2005, 2008). Thus, it is important for host tissues to have the capacity to regulate the accumulation of ROS to nontoxic amounts to optimize immune cell function.

Antioxidant mechanisms include a complex network of factors that have the capacity to inactivate harmful ROS produced through normal cellular activities and during times of immune cell activation to invading pathogens. Several vitamins and trace minerals are essential components of the antioxidant defense system and deficiencies in any of these micronutrients are associated with compromised immune and increased susceptibility to diseases in dairy cattle (Spears and Weiss, 2008). In general, the antioxidant functions of vitamins and minerals can be characterized as having the capacity to quench oxidants directly or form part of enzymatic redox couples that convert ROS to less reactive metabolites (Table 3). Some examples of radical scavengers derived or associated with various micronutrients include tocopherols, ascorbic acid, carotenoids, and glutathione. Important ROS detoxifying enzymes systems also associated with micronutrients include catalase, superoxide dismutase, and seleniumdependent enzymes systems (Sordillo and Aitken, 2009). Among the widely studied antioxidant defense mechanisms in dairy cattle are the selenium-dependent enzyme systems, such as cytosolic glutathione peroxidase (GPX1) and thioredoxin reductase (TRX1), which have selenocysteine residues incorporated into their active sites. Both GPX1 and TRX1 function by reducing $\mathrm{H}_{2} \mathrm{O}_{2}$ and fatty acid hydroperoxides to less reactive water and alcohols, respectively. For example, GPX1 can reduce a large spectrum of hydroperoxides at the expense of its redox couple, glutathione. Alternatively, oxidized cysteine groups on proteins can be reduced using the redox-active center of thioredoxin to form disulfide bonds that are in turn reduced by TRX1 and NADPH (Sordillo and Aitken, 2009). Other enzyme systems that play a critical role in preventing the formation of oxygen radicals include the Fe-containing catalase, cytosolic superoxide dismutase (copper and zinc), and mitochondrial superoxide dismutase (manganese and zinc). Antioxidants also function as free radical scavengers when they stabilize ROS by donating an electron, thus becoming an oxidized but more stable radical. For example, $\alpha$-tocopherol (vitamin E) scavenges lipid peroxy radicals by donating a hydrogen ion and is then converted to a tocopherol radical. The tocopherol radical can then be regenerated back to its reduced form by ascorbic acid (vitamin C). Thus, ascorbic acid plays a key role in maintaining the redox state of cells in addition to functioning as a free radical scavenger for other oxidized biomolecules (Sordillo and Aitken, 2009). The vitamin A precursor $\beta$-carotene is another important free radical scavenger. Carotenoids are especially effective at quenching singlet oxygen and can prevent formation of secondary ROS. Although micronutrients are essential components of the antioxidant defense network, it is significant to note that plasma concentrations of vitamins and minerals tend to decrease in dairy cows around the time of parturition. The decrease in available serum-derived micronutrients is likely a combination of reduced dietary intakes as well as increased rates of utilization associated with metabolic stress in transition cows (Spears and Weiss, 
2008; Sordillo and Mavangira, 2014). Concentrations of vitamins and minerals that must be supplemented to dairy cattle diets should be based not only on what is adequate to maximize production efficiency but also what is required by the immune system to prevent oxidative stress and optimize immune cell functions.

\section{Measuring Immune Status and Function}

Developing effective nutritional-based strategies to optimize dairy cattle immunity requires reliable and accurate ways to measure immune competence. Because of the complexity of the immune system, many different ways exist to assess both innate and adaptive immune responses. Several general approaches can be used to evaluate the immune status of dairy cows in response to nutritional intervention strategies. First, the blood compartment is the pipeline of the immune system and the simplest approach is to profile cellular and soluble immune components in blood. Although not specific for source of infection, normal and elevated ranges for blood leukocyte counts and circulating concentrations of acute phase proteins are well established, and measuring changes in these blood parameters is used routinely in veterinary medicine to assess immune status. Another widely used approach to assess immune function in dairy cattle is the isolation of immune cells from the blood and then studying their activity in vitro. Many different laboratory assays are available to determine both innate and adaptive bovine immune capabilities. Techniques for assessing immune capacity could be direct by measuring the functional capacity of isolated immune cells. Additional insight into immune capacity can be gained by evaluating the phenotype of peripheral blood or local leukocyte populations using flow cytometry. The most direct method of evaluating immune status, however, is to study how cows respond in vivo following an immune challenge. Administering a vaccine is a form of immune challenge that can be assessed by measuring antigen-specific antibodies. Another direct approach would be to evaluate the pattern of disease susceptibility or degree of pathogenesis as related to the altered functional capacity of specific immune responses. An exciting and relatively new area of assessing changes in immune status in dairy cattle during health and disease includes the use of highthroughput molecular and cellular profiling tools. Over the last decade, the application of genomic, proteomic, and metabolomic methodology has revolutionized our current understanding of important immune responses in several disease models of economic importance to the dairy industry (Sordillo and Mullarky, 2010; Boggess et al., 2013; Thompson-Crispi et al., 2014).
Whereas a multitude of methods exist to assess immune responses to nutritional interventions, defining the best indicators of immune status is impeded by several factors. Proper interpretation of any immune assessment must be based on established cut-off values for normal and abnormal ranges. Unfortunately, many physiological and environmental factors can affect immunity and such established ranges are not currently available. There also exists considerable individual animal variation with certain immune assessments, even when assessed within a singular herd. Finally, many of the methods to assess immune function are conducted in different laboratories that make comparisons between studies difficult to assess in terms of absolute values. As key immune responses in dairy cows are identified that are critical to optimizing disease resistance, it may be possible to provide more uniform and standardized assays that are accurate predictors of immune status.

\section{CONCLUSIONS}

Although a direct causal link has not been established in cattle, ample evidence suggests that the increase in both metabolic and infectious diseases during the transition period is symptomatic of dysfunctional host immune defenses due to altered nutritional status and nutrient metabolism. Thus, better understanding of the multifactorial interactions between dairy cattle nutrition and immunity can lead to more effective management strategies to control health disorders around the time of calving. Considerable research has established that metabolic stress during the periparturient period in dairy cattle is closely associated with dysfunction of several components of the innate and adaptive immune response. Certain hormones associated with parturition can explain some of the adverse effects on immunity during the periparturient period. However, severe deficits in both macro- and micronutrients as a consequence of reduced DMI and NEB have a pronounced effect on host defense mechanisms and health disorders in early lactation. Activation of the immune response also requires energy, and the immune system must compete for essential nutrients that are otherwise being used for growth, muscle accretion, and milk production. The development of uncontrolled acute or chronic inflammatory responses to infectious pathogens may not only cause bystander damage to host tissues but it can also repartition nutrients, resulting in dramatic reductions in animal growth and productivity. Therefore, adjusting the nutrition of animals and improving management to reduce immunological challenges can have a major effect on optimizing immunity and disease resistance in transition cows. Whereas antibiotic therapy 
remains the mainstay for the treatment of many infectious diseases, alternative and adjunct therapeutic options are needed that target host immune responses. The development of nutritional-based strategies that can enhance an otherwise impaired immune response will have a prominent role in food animal agriculture. The challenge, however, is to discover how to selectively down-modulate harmful host responses without diminishing beneficial responses that facilitate elimination of invading pathogens. In contrast to antimicrobial drugs used to treat diseases in food animals, strategies that target host responses through nutrition will minimize the risk of drug residues and the possibility of developing drug-resistant pathogens.

\section{ACKNOWLEDGMENTS}

This work was funded in part by grants 2011-6701530179 and 2014-68004-21972 from the Agriculture and Food Research Initiative Competitive Grants Programs of the USDA National Institute for Food and Agriculture (Washington, DC) and by an endowment from the Matilda R. Wilson Fund (Detroit, MI).

\section{REFERENCES}

Aitken, S. L., C. M. Corl, and L. M. Sordillo. 2011. Immunopathology of mastitis: Insights into disease recognition and resolution. J. Mammary Gland Biol. Neoplasia 16:291-304.

Anderson, B. H., D. L. Watson, and I. G. Colditz. 1999. The effect of dexamethasone on some immunological parameters in cattle. Vet. Res. Commun. 23:399-413.

Andrieu, S. 2008. Is there a role for organic trace element supplements in transition cow health? Vet. J. 176:77-83.

Arnardottir, H., S. K. Orr, J. Dalli, and C. N. Serhan. 2015. Human milk proresolving mediators stimulate resolution of acute inflammation. Mucosal Immunol.http://dx.doi.org/10.1038/mi.2015.99.

Babior, B. M. 1999. NADPH oxidase: An update. Blood 93:1464-1476.

Baldwin, C. L., and J. C. Telfer. 2015. The bovine model for elucidating the role of $\gamma \delta \mathrm{T}$ cells in controlling infectious diseases of importance to cattle and humans. Mol. Immunol. 66:35-47.

Bannerman, D. D. 2009. Pathogen-dependent induction of cytokines and other soluble inflammatory mediators during intramammary infection of dairy cows. J. Anim. Sci. 87(Suppl.):10-25.

Bernabucci, U., B. Ronchi, N. Lacetera, and A. Nardone. 2005. Influence of body condition score on relationships between metabolic status and oxidative stress in periparturient dairy cows. J. Dairy Sci. 88:2017-2026

Boggess, M. V., J. D. Lippolis, W. J. Hurkman, C. K. Fagerquist, S. P. Briggs, A. V. Gomes, P. G. Righetti, and K. Bala. 2013. The need for agriculture phenotyping: "Moving from genotype to phenotype". J. Proteomics 93:20-39.

Boutet, P., F. Bureau, G. Degand, and P. Lekeux. 2003. Imbalance between lipoxin A4 and leukotriene B4 in chronic mastitis-affected cows. J. Dairy Sci. 86:3430-3439.

Brand, K. 1985. Glutamine and glucose metabolism during thymocyte proliferation. Pathways of glutamine and glutamate metabolism. Biochem. J. 228:353-361.

Brown, D. I., and K. K. Griendling. 2015. Regulation of signal transduction by reactive oxygen species in the cardiovascular system. Circ. Res. 116:531-549.
Burton, J. L., M. E. Kehrli Jr., S. Kapil, and R. L. Horst. 1995 Regulation of L-selectin and CD18 on bovine neutrophils by glucocorticoids: Effects of cortisol and dexamethasone. J. Leukoc. Biol. $57: 317-325$.

Burton, J. L., S. A. Madsen, L. C. Chang, P. S. Weber, K. R. Buckham, R. van Dorp, M. C. Hickey, and B. Earley. 2005. Gene expression signatures in neutrophils exposed to glucocorticoids: a new paradigm to help explain "neutrophil dysfunction" in parturient dairy cows. Vet. Immunol. Immunopathol. 105:197-219.

Cai, T. Q., P. G. Weston, L. A. Lund, B. Brodie, D. J. McKenna, and W. C. Wagner. 1994. Association between neutrophil functions and periparturient disorders in cows. Am. J. Vet. Res. 55:934-943.

Calder, P. C. 2013. Feeding the immune system. Proc. Nutr. Soc. 72:299-309.

Calder, P. C., G. Dimitriadis, and P. Newsholme. 2007. Glucose metabolism in lymphoid and inflammatory cells and tissues. Curr. Opin. Clin. Nutr. Metab. Care 10:531-540.

Catalani, E., M. Amadori, A. Vitali, and N. Lacetera. 2013. Short communication: Lymphoproliferative response to lipopolysaccharide and incidence of infections in periparturient dairy cows. J. Dairy Sci. 96:7077-7081.

Clarke, S. D. 2004. The multi-dimensional regulation of gene expression by fatty acids: Polyunsaturated fats as nutrient sensors. Curr. Opin. Lipidol. 15:13-18.

Contreras, G. A., S. A. Mattmiller, W. Raphael, J. C. Gandy, and L. M. Sordillo. 2012a. Enhanced n-3 phospholipid content reduces inflammatory responses in bovine endothelial cells. J. Dairy Sci 95:7137-7150

Contreras, G. A., N. J. O’Boyle, T. H. Herdt, and L. M. Sordillo. 2010 Lipomobilization in periparturient dairy cows influences the composition of plasma nonesterified fatty acids and leukocyte phospholipid fatty acids. J. Dairy Sci. 93:2508-2516.

Contreras, G. A., W. Raphael, S. A. Mattmiller, J. Gandy, and L. M. Sordillo. 2012b. Nonesterified fatty acids modify inflammatory response and eicosanoid biosynthesis in bovine endothelial cells. J. Dairy Sci. 95:5011-5023.

Curtis, C. R., H. N. Erb, C. J. Sniffen, R. D. Smith, P. A. Powers, M. C. Smith, M. E. White, R. B. Hillman, and E. J. Pearson. 1983 Association of parturient hypocalcemia with eight periparturient disorders in Holstein cows. J. Am. Vet. Med. Assoc. 183:559-561.

Davis, S. L. 1998. Environmental modulation of the immune system via the endocrine system. Domest. Anim. Endocrinol. 15:283-289.

Dirandeh, E., A. Towhidi, Z. Ansari Pirsaraei, F. Adib Hashemi, M. Ganjkhanlou, S. Zeinoaldini, A. Rezaei Roodbari, T. Saberifar, and H. V. Petit. 2013. Plasma concentrations of PGFM and uterine and ovarian responses in early lactation dairy cows fed omega-3 and omega-6 fatty acids. Theriogenology 80:131-137.

Drackley, J. K. 1999. ADSA Foundation Scholar Award. Biology of dairy cows during the transition period: The final frontier? J. Dairy Sci. 82:2259-2273.

Emanuelson, U., P. A. Oltenacu, and Y. T. Grohn. 1993. Nonlinear mixed model analyses of five production disorders of dairy cattle. J. Dairy Sci. 76:2765-2772.

Erridge, C., and N. J. Samani. 2009. Saturated fatty acids do not directly stimulate toll-like receptor signaling. Arterioscler. Thromb. Vasc. Biol. 29:1944-1949.

Finkel, T. 2011. Signal transduction by reactive oxygen species. J. Cell Biol. 194:7-15.

Grinberg, N., S. Elazar, I. Rosenshine, and N. Y. Shpigel. 2008. Betahydroxybutyrate abrogates formation of bovine neutrophil extracellular traps and bactericidal activity against mammary pathogenic Escherichia coli. Infect. Immun. 76:2802-2807.

Grommers, F. J., D. Van de Geer, H. Van der Vliet, P. A. Henricks, and F. P. Nijkamp. 1989. Polymorphonuclear leucocyte function: Relationship between induced migration into the bovine mammary gland and in vitro cell activity. Vet. Immunol. Immunopathol. $23: 75-83$.

Gross, J., H. A. van Dorland, F. J. Schwarz, and R. M. Bruckmaier. 2011. Endocrine changes and liver mRNA abundance of somatotropic axis and insulin system constituents during negative energy 
balance at different stages of lactation in dairy cows. J. Dairy Sci. 94:3484-3494.

Grum, D. E., J. K. Drackley, and J. H. Clark. 2002. Fatty acid metabolism in liver of dairy cows fed supplemental fat and nicotinic acid during an entire lactation. J. Dairy Sci. 85:3026-3034.

Hagiwara, S., K. Mori, H. Okada, S. Oikawa, and H. Nagahata. 2014. Acute Escherichia coli mastitis in dairy cattle: Diagnostic parameters associated with poor prognosis. J. Vet. Med. Sci. 76:14311436.

Hajishengallis, G., and J. D. Lambris. 2010. Crosstalk pathways between Toll-like receptors and the complement system. Trends Immunol. 31:154-163.

Hammon, D. S., I. M. Evjen, T. R. Dhiman, J. P. Goff, and J. L. Walters. 2006. Neutrophil function and energy status in Holstein cows with uterine health disorders. Vet. Immunol. Immunopathol. 113:21-29.

Heuer, C., Y. H. Schukken, and P. Dobbelaar. 1999. Postpartum body condition score and results from the first test day milk as predictors of disease, fertility, yield, and culling in commercial dairy herds. J. Dairy Sci. 82:295-304.

Hill, A. W. 1981. Factors influencing the outcome of Escherichia coli mastitis in the dairy cow. Res. Vet. Sci. 31:107-112.

Hodgkinson, A. J., E. A. Carpenter, C. S. Smith, P. C. Molan, and C. G. Prosser. 2007. Adhesion molecule expression in the bovine mammary gland. Vet. Immunol. Immunopathol. 115:205-215.

Hodgson, K., J. Morris, T. Bridson, B. Govan, C. Rush, and N. Ketheesan. 2015. Immunological mechanisms contributing to the double burden of diabetes and intracellular bacterial infections. Immunology 144:171-185.

Hoedemaker, M., D. Prange, and Y. Gundelach. 2009. Body condition change ante- and postpartum, health and reproductive performance in German Holstein cows. Reprod. Domest. Anim. 44:167173.

Ingvartsen, K. L., and J. B. Andersen. 2000. Integration of metabolism and intake regulation: A review focusing on periparturient animals. J. Dairy Sci. 83:1573-1597.

Ingvartsen, K. L., and K. Moyes. 2013. Nutrition, immune function and health of dairy cattle. Animal 7(Suppl. 1):112-122.

Jungi, T. W., K. Farhat, I. A. Burgener, and D. Werling. 2011. Tolllike receptors in domestic animals. Cell Tissue Res. 343:107-120.

Kawai, T., and S. Akira. 2011. Toll-like receptors and their crosstalk with other innate receptors in infection and immunity. Immunity 34:637-650.

Kazansky, D. B. 2008. MHC restriction and allogeneic immune responses. J. Immunotoxicol. 5:369-384.

Kehrli, M. E. Jr., B. J. Nonnecke, and J. A. Roth. 1989. Alterations in bovine neutrophil function during the periparturient period. Am. J. Vet. Res. 50:207-214.

Kelley, K. W., D. A. Weigent, and R. Kooijman. 2007. Protein hormones and immunity. Brain Behav. Immun. 21:384-392.

Kimura, K., J. P. Goff, and M. E. Kehrli Jr.. 1999. Effects of the presence of the mammary gland on expression of neutrophil adhesion molecules and myeloperoxidase activity in periparturient dairy cows. J. Dairy Sci. 82:2385-2392.

Kimura, K., J. P. Goff, M. E. Kehrli Jr., J. A. Harp, and B. J. Nonnecke. 2002b. Effects of mastectomy on composition of peripheral blood mononuclear cell populations in periparturient dairy cows. J. Dairy Sci. 85:1437-1444.

Kimura, K., J. P. Goff, M. E. Kehrli Jr., and T. A. Reinhardt. 2002a. Decreased neutrophil function as a cause of retained placenta in dairy cattle. J. Dairy Sci. 85:544-550.

Kumar, H., T. Kawai, and S. Akira. 2011. Pathogen recognition by the innate immune system. Int. Rev. Immunol. 30:16-34.

Lamote, I., E. Meyer, A. De Ketelaere, L. Duchateau, and C. Burvenich. 2006a. Expression of the estrogen receptor in blood neutrophils of dairy cows during the periparturient period. Theriogenology 65:1082-1098.

Lamote, I., E. Meyer, A. De Ketelaere, L. Duchateau, and C. Burvenich. 2006b. Influence of sex steroids on the viability and CD11b, CD18 and CD47 expression of blood neutrophils from dairy cows in the last month of gestation. Vet. Res. 37:61-74.
Lee, J. Y., L. Zhao, and D. H. Hwang. 2010. Modulation of pattern recognition receptor-mediated inflammation and risk of chronic diseases by dietary fatty acids. Nutr. Rev. 68:38-61.

Lessard, M., N. Gagnon, D. L. Godson, and H. V. Petit. 2004. Influence of parturition and diets enriched in n- 3 or n- 6 polyunsaturated fatty acids on immune response of dairy cows during the transition period. J. Dairy Sci. 87:2197-2210.

Lippolis, J. D., B. D. Peterson-Burch, and T. A. Reinhardt. 2006a. Differential expression analysis of proteins from neutrophils in the periparturient period and neutrophils from dexamethasone-treated dairy cows. Vet. Immunol. Immunopathol. 111:149-164.

Lippolis, J. D., T. A. Reinhardt, J. P. Goff, and R. L. Horst. 2006b. Neutrophil extracellular trap formation by bovine neutrophils is not inhibited by milk. Vet. Immunol. Immunopathol. 113:248-255.

Luo, C., K. Wang, Q. Liu, Y. Li, and Q. S. Zhao. 2008. The functional roles of lipid rafts in T cell activation, immune diseases and HIV infection and prevention. Cell. Mol. Immunol. 5:1-7.

Maddox, J. F., K. M. Aherne, C. C. Reddy, and L. M. Sordillo. 1999 Increased neutrophil adherence and adhesion molecule mRNA expression in endothelial cells during selenium deficiency. J. Leukoc. Biol. 65:658-664.

Mallard, B. A., J. C. Dekkers, M. J. Ireland, K. E. Leslie, S. Sharif, C. L. Vankampen, L. Wagter, and B. N. Wilkie. 1998. Alteration in immune responsiveness during the peripartum period and its ramification on dairy cow and calf health. J. Dairy Sci. 81:585-595.

Mattos, R., C. R. Staples, A. Arteche, M. C. Wiltbank, F. J. Diaz, T. C. Jenkins, and W. W. Thatcher. 2004. The effects of feeding fish oil on uterine secretion of $\mathrm{PGF}_{2 \alpha}$, milk composition, and metabolic status of periparturient Holstein cows. J. Dairy Sci. 87:921-932.

Mavangira, V., J. C. Gandy, C. Zhang, V. E. Ryman, A. Daniel Jones, and L. M. Sordillo. 2015. Polyunsaturated fatty acids influence differential biosynthesis of oxylipids and other lipid mediators during bovine coliform mastitis. J. Dairy Sci. 98:6202-6215.

McGuire, K., M. Jones, D. Werling, J. L. Williams, E. J. Glass, and O. Jann. 2006. Radiation hybrid mapping of all 10 characterized bovine Toll-like receptors. Anim. Genet. 37:47-50.

Mehrzad, J., H. Dosogne, E. Meyer, R. Heyneman, and C. Burvenich. 2001. Respiratory burst activity of blood and milk neutrophils in dairy cows during different stages of lactation. J. Dairy Res. 68:399-415.

Moyes, K. M., J. K. Drackley, J. L. Salak-Johnson, D. E. Morin, J. C. Hope, and J. J. Loor. 2009. Dietary-induced negative energy balance has minimal effects on innate immunity during a Streptococcus uberis mastitis challenge in dairy cows during midlactation. J. Dairy Sci. 92:4301-4316.

Newsholme, P., R. Curi, S. Gordon, and E. A. Newsholme. 1986. Metabolism of glucose, glutamine, long-chain fatty acids and ketone bodies by murine macrophages. Biochem. J. 239:121-125.

Nonnecke, B. J., K. Kimura, J. P. Goff, and M. E. Kehrli Jr.. 2003 Effects of the mammary gland on functional capacities of blood mononuclear leukocyte populations from periparturient cows. J. Dairy Sci. 86:2359-2368.

O'Boyle, N. J., G. A. Contreras, S. A. Mattmiller, and L. M. Sordillo. 2012. Changes in glucose transporter expression in monocytes of periparturient dairy cows. J. Dairy Sci. 95:5709-5719.

Oltenacu, P. A., and I. Ekesbo. 1994. Epidemiological study of clinical mastitis in dairy cattle. Vet. Res. 25:208-212.

Pattanaik, U., and K. Prasad. 1998. Oxygen free radicals and endotoxic shock: Effect of flaxseed. J. Cardiovasc. Pharmacol. Ther. 3:305-318.

Perkins, K. H., M. J. VandeHaar, J. L. Burton, J. S. Liesman, R. J. Erskine, and T. H. Elsasser. 2002. Clinical responses to intramammary endotoxin infusion in dairy cows subjected to feed restriction. J. Dairy Sci. 85:1724-1731.

Perkins, K. H., M. J. VandeHaar, R. J. Tempelman, and J. L. Burton. 2001. Negative energy balance does not decrease expression of leukocyte adhesion or antigen-presenting molecules in cattle. J. Dairy Sci. 84:421-428.

Pinedo, P. J., A. De Vries, and D. W. Webb. 2010. Dynamics of culling risk with disposal codes reported by Dairy Herd Improvement dairy herds. J. Dairy Sci. 93:2250-2261. 
Pritchett, J. G., D. D. Thilmany, and K. K. Johnson. 2005. Animal disease economic impacts: A survey of literature and typology of research approaches. Int. Food Agribus. Manage. Rev. 8:23-45.

Rainard, P. 2003. The complement in milk and defense of the bovine mammary gland against infections. Vet. Res. 34:647-670.

Rainard, P., and C. Riollet. 2006. Innate immunity of the bovine mammary gland. Vet. Res. 37:369-400.

Raphael, W., and L. M. Sordillo. 2013. Dietary polyunsaturated fatty acids and inflammation: The role of phospholipid biosynthesis. Int. J. Mol. Sci. 14:21167-21188.

Roche, J. R., N. C. Friggens, J. K. Kay, M. W. Fisher, K. J. Stafford and D. P. Berry. 2009. Invited review: Body condition score and its association with dairy cow productivity, health, and welfare. J. Dairy Sci. 92:5769-5801.

Roth, J. A., M. L. Kaeberle, and W. H. Hsu. 1982. Effect of estradiol and progesterone on lymphocyte and neutrophil functions in steers. Infect. Immun. 35:997-1002.

Ryman, V. E., N. Packiriswamy, and L. M. Sordillo. 2015a. Role of endothelial cells in bovine mammary gland health and disease. Anim. Health Res. Rev. http://dx.doi.org/10.1017/S1466252315000158.

Ryman, V. E., G. M. Pighetti, J. D. Lippolis, J. C. Gandy, C. M. Applegate, and L. M. Sordillo. 2015b. Quantification of bovine oxylipids during intramammary Streptococcus uberis infection. Prostaglandins Other Lipid Mediat.http://dx.doi.org/10.1016/j. prostaglandins.2015.09.006.

Serhan, C. N., and N. Chiang. 2008. Endogenous pro-resolving and anti-inflammatory lipid mediators: A new pharmacologic genus. Br. J. Pharmacol. 153(Suppl. 1):S200-S215.

Serhan, C. N., N. Chiang, and T. E. Van Dyke. 2008. Resolving inflammation: Dual anti-inflammatory and pro-resolution lipid mediators. Nat. Rev. Immunol. 8:349-361.

Shuster, D. E., E. K. Lee, and M. E. Kehrli Jr.. 1996. Bacterial growth, inflammatory cytokine production, and neutrophil recruitment during coliform mastitis in cows within ten days after calving, compared with cows at midlactation. Am. J. Vet. Res. 57:1569 1575.

Silvestre, F. T., T. S. Carvalho, P. C. Crawford, J. E. Santos, C. R Staples, T. Jenkins, and W. W. Thatcher. 2011. Effects of differential supplementation of fatty acids during the peripartum and breeding periods of Holstein cows: II. Neutrophil fatty acids and function, and acute phase proteins. J. Dairy Sci. 94:2285-2301.

Sordillo, L. M., and S. L. Aitken. 2009. Impact of oxidative stress on the health and immune function of dairy cattle. Vet. Immunol. Immunopathol. 128:104-109.

Sordillo, L. M., and V. Mavangira. 2014. The nexus between nutrient metabolism, oxidative stress and inflammation in transition cows. Anim. Prod. Sci. 54:1204-1214.
Sordillo, L. M., and I. K. Mullarky. 2010. Cutting edge technologies in animalomics. Vet. Immunol. Immunopathol. 138:239-240.

Sordillo, L. M., N. O'Boyle, J. C. Gandy, C. M. Corl, and E. Hamilton. 2007. Shifts in thioredoxin reductase activity and oxidant status in mononuclear cells obtained from transition dairy cattle. J. Dairy Sci. 90:1186-1192.

Sordillo, L. M., and W. Raphael. 2013. Significance of metabolic stress lipid mobilization, and inflammation on transition cow disorders. Vet. Clin. North Am. Food Anim. Pract. 29:267-278.

Sordillo, L. M., and K. L. Streicher. 2002. Mammary gland immunity and mastitis susceptibility. J. Mammary Gland Biol. Neoplasia $7: 135-146$

Sordillo, L. M., K. L. Streicher, I. K. Mullarky, J. C. Gandy, W. Trigona, and C. M. Corl. 2008. Selenium inhibits 15-hydroperoxyoctadecadienoic acid-induced intracellular adhesion molecule expression in aortic endothelial cells. Free Radic. Biol. Med. 44:34-43.

Sordillo, L. M., J. A. Weaver, Y. Z. Cao, C. Corl, M. J. Sylte, and I. K. Mullarky. 2005. Enhanced 15-HPETE production during oxidant stress induces apoptosis of endothelial cells. Prostaglandins Other Lipid Mediat. 76:19-34

Spears, J. W., and W. P. Weiss. 2008. Role of antioxidants and trace elements in health and immunity of transition dairy cows. Vet. J. 176:70-76

Summers, C., S. M. Rankin, A. M. Condliffe, N. Singh, A. M. Peters, and E. R. Chilvers. 2010. Neutrophil kinetics in health and disease. Trends Immunol. 31:318-324.

Takeuchi, O., and S. Akira. 2010. Pattern recognition receptors and inflammation. Cell 140:805-820.

Thompson-Crispi, K., H. Atalla, F. Miglior, and B. A. Mallard. 2014 Bovine mastitis: Frontiers in immunogenetics. Front. Immunol. 5:493. http://dx.doi.org/10.3389/fimmu.2014.00493.

Valko, M., D. Leibfritz, J. Moncol, M. T. Cronin, M. Mazur, and J. Telser. 2007. Free radicals and antioxidants in normal physiological functions and human disease. Int. J. Biochem. Cell Biol. 39:44-84.

Weaver, J. A., J. F. Maddox, Y. Z. Cao, I. K. Mullarky, and L. M. Sordillo. 2001. Increased 15-HPETE production decreases prostacyclin synthase activity during oxidant stress in aortic endothelial cells. Free Radic. Biol. Med. 30:299-308.

Weigent, D. A. 2013. Lymphocyte GH-axis hormones in immunity. Cell. Immunol. 285:118-132.

Wilde, D. 2006. Influence of macro and micro minerals in the periparturient period on fertility in dairy cattle. Anim. Reprod. Sci. 96:240-249.

Zhao, X. J., Z. P. Li, J. H. Wang, X. M. Xing, Z. Y. Wang, L. Wang, and Z. H. Wang. 2015. Effects of chelated $\mathrm{Zn} / \mathrm{Cu} / \mathrm{Mn}$ on redox status, immune responses and hoof health in lactating Holstein cows. J. Vet. Sci. 16:439-446. 